important topics. This has produced an attractive arrangement for reading, but the reason for choosing some of the subheadings is not clear, and an index would have improved the presentation. To compensate, there is an extensive list of portinent references in an appondix. Photographs and diagrams are excellent throughout.

As is true for most symposia records, this one will be of most value for those wishing to become acquainted quickly with the principal lines of investigation. Clinicians and biologists will probably derive most benefit, while engineers may conelude that there is still a lot to be learnt about the physiology of diarthrodial joints.

C. C̆x. Woons

\section{NEW NUCLEAR TEXT}

\section{Nuclear Electronics}

By E.Kowalski. Pp. x402. (Springer-Verlag: Berlin New York, 1970) $96 \mathrm{DM} ; \$ 26.40$.

I used to start my courses on electronics by ritually smashing a valve with a hammer. I don't do it now because there was always a slight danger in the procedure and the message about transistors has reached all but the most reactionary quarters. If, and it must be said that the style, presentation and general quality of production are a formidable inhibitory influence, one were to extend the principle to the work by Dr. Kowalski, there would be little to do for the book is up-to-date and illustrates most of the techniques with diagrams showing integrated circuits or transistors.

The author starts by giving the theoretical background to radiation detectors but in this, as in the work as a whole, he fully illustrates the argument with circuit diagrams. In the introduction he had made the point that it is never too soon to get away from the vagaries of analogue circuits into the sweet certainty of digital representation and in the middle section he makes much of the tools, both technical and mathematical by which the transformation may be accomplished. The last section of the work contains a comprehensive review of digital techniques complete with a note on Boolean algebra.

As small digital computers are changing the approach to the problem of processing digital information at the same frenic rate that transisters have changed the methods and scope of instrumentation, it would be churlish to complain that the section on them is too short, particularly in view of the quality of the background information on digital circuits in general. Nevertheless it is possible to see that this section should, in future editions, be enlarged.

It is stated in the preface that one of the aims of the text is that it should be useful as a reference work in years to come and the extensive references must alone make this a strong possibility. The list includes more than 900 entries most of which have been published within the last three or four years. Altogether the book is to be recommended as an important and timely addition to the literature of the subject.

Lindsay Molyneux

This review has been set by the combination of a 'Micro 16' computer (Digico Ltd) directly interfaced with the photo-unit of a 'Linotron 505' typesetting machine. The computer, as well as deciding the line endings and adjusting the spaces for justification, also simulated the functions of the logic unit of the 505 . Because the first proof (set in 39 seconds) contained an error, a second proof was made using the ADDATAPE correction system; this took 44 seconds. The programs and interface were developed by Dr Molyneux in the School of Physics, University of Newcastle upon Tyne, during a Ministry of Technology Computer Typesetting Research Contract.

\section{ORGANIC CHEMISTRY REVIEWS}

\section{Topics in Carbocyclic Chemistry}

Vol. 1. Edited by D. Lloyd. Pp. xi +373. (Logos Press, in association with Elek Books: London, 1969.) $125 \mathrm{~s}$.

Is recent years an increasing number of publications devoted to reviewing specific areas of organic chemistry has appeared. These are, on the whole, welcomed by organic chemists because they relieve to some extent the ever-growing burden of the original literaturc. This book is the first of a scries which is to provide reviews in the field of carbocyclic chemistry. The series is entitled "Topics" rather than "Advances" because tho articles are intended to "present the subject with sufficient background to make them acceptable to all readers". In my opinion this distinetion is somewhat pedantic becauso most comprehensive reviews, even of the recent literature, would more or less satisfy this demand.

The necessity for a publication of this type is also debatable because its usefulness to a particular chemist will be severely limited by the enormous scope of the field of carbocyclic chemistry. Of the articles in the current volume, that on tho benzidine rearrangement, for example, could easily have found a place in Advances in Physical Organic Chemistry, and that on bicyclo[3.3.1]nonanes would have been suitable for Advances in Alicyclic Chemistry.

Aside from this carping, the book, which is excellently produced, will be a valuable addition to any chemical library. The standard of the individual articles is high and they mostly cover the literature up to 1968 with more recent work in addenda. D. V. Banthorpe in "The Benzidine Rearrangement" provides a comprehensive and critical account of this problem which has now beset chemists for more than a hundred years. D. H. G. Crout, in "The Biosynthesis of Carbocyclic Compounds", has performed the difficult task of compressing a vast amount of material into an intelligible account. Of necessity there aro various incursions into the domain of heterocyclic chemistry. G. L. Buchanan, in "Bicyclo[3.3.1]nonanes and Related Compounds", entertains the reader to a lucid account of these interesting systems, and D. M. G. Lloyd provides a short article on "Feist's Acid".

II. P. Figeys, in an article entitled "Electronic Structure and Spectral Properties of Annulenes and Related Compounds", presents a critique of the theorctical chemistry of the annulenes which is both readable and intelligible to the experimental organic chemist. Particular attention is devoted to antiaromaticity as is merited by recent interest in this area. Breslow's speculations on the fusion of two 4n systems are dismissed as "two wrongs do not make a right". Much discussion is devoted to the red herring of benzo-annelated systems whereas the annulenyl and annulenium ions are unfortunately entirely omitted.

M. V. SARGENT

\section{REFRACTORY METALS}

Properties of Refractory Metals

By Walter D. Wilkinson. Pp. $x+355$. (Gordon and Breach: New York and London, November 1969.) $\$ 33 ; 275 s$.

THE text of this book was completed in May 1967 (but not published until November 1969) under the direction of the American Society for Metals on behalf of the United States Atomic Energy Commission. It is consequently a book on refractory metals for use in nuclear reactors and covers vanadium, chromium, niobium, molybdenum, tantalum and tungsten. A somewhat pedantic choice of $a$ lower melting limit of $1,855^{\circ} \mathrm{C}$ for deciding the metals to be discussed results in the exclusion of zirconium (m.p. $1,852^{\circ} \mathrm{C}$ ) and the inclusion of chromium (m.p. $1,875^{\circ} \mathrm{C}$ ). This seems to be straining to rationalize a choice that 